\title{
Social assistance systems in crisis situations: resilient, responsive and sensitive?
}

\author{
Rachel Slater and Daniel Longhurst
}

\author{
February 2022
}

\section{Theme summary}

Evidence on what enables social assistance systems to deliver routinely, effectively and efficiently is limited in crisis situations. Shock-responsive social protection (SRSP) and adaptive social protection (ASP) have become popular in global and national development discourses. Yet, their operationalisation in protracted crises is narrow and less well understood.

Regarding SRSP, focus has shifted towards how existing social protection programmes might be scaled and flexed in crisis situations. However, the focus seems fixed entirely on what makes social protection and humanitarian assistance responsive to the detriment of understanding what makes those systems resilient and able to maintain business continuity in protracted crises. Little attention is paid to how to sustain delivery of existing programmes, on which millions of poor and vulnerable households depend.

By exploring experiences in a range of countries, BASIC Research has identified knowledge gaps related to: (i) the considerations that are important for working out when to attempt SRSP in fragile and conflict-affected settings (FCAS); (ii) the factors and systems features that enable existing social assistance delivery to be resilient to shocks and stresses; and (iii) how social assistance systems can be more sensitive in their design and delivery to the realities of operating in situations of protracted crises.

This thematic brief is a shortened version of two BASIC Research Working Papers. To explore this research theme in more detail please refer to:

Longhurst, D. and Slater, R. (2022) Shock-Responsive Social Protection: What is Known About What Works in Fragile and ConflictAffected Situations?, BASIC Research Working Paper 5, Brighton: Institute of Development Studies, DOI: 10.19088/BASIC.2022.005

Slater, R. (2022) Sustaining Existing Social Protection Programmes During Crises: What Do We Know? How Can We Know More?, BASIC Research Working Paper 14, Brighton: Institute of Development Studies, DOI: 10.19088/BASIC.2022.014

A full list of the references cited in this brief can be found at the BASIC Research Zotero library.

Implemented by
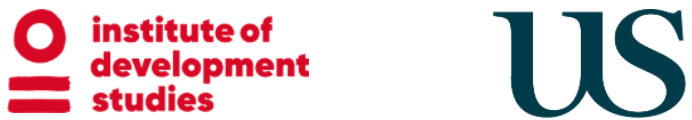

UNIVERSITY

OF SUSSEX
UNIVERSITY OF WOLVERHAMPTON

Better Assistance in Crises (BASIC) Research (funded by UKAid) aims to inform policy and programming on how to help poor and vulnerable people cope better with crises and meet their basic needs through more effective social assistance. All costs related to BASIC Research are covered by the UK Foreign, Commonwealth and Development Office. 


\section{State of the evidence and debate}

Crisis-resilient social assistance systems

There is very limited direct treatment of the question of if and how delivery of existing social protection programmes is sustained in crisis situations. Although many studies consider using social protection responses in crisis contexts, few explore how crises themselves affect social protection systems (Hu et al. 2010)

In 2020, global attention on social protection in COVID-19 responses was dominated by programme expansion and the development of new programmes. Despite substantial noise about vertical and horizontal expansions, both globally and regionally, in fact, much of the work in social protection was dedicated to sustaining existing delivery (Rodolof et al. 2021) - but this aspect received far less attention.
Crisis-responsive social assistance systems

A host of factors (timeliness in lifethreatening situations, risky operating principles, territorial control, lack of legislation, limited domestic capacity and weak systems) mean that where examples do exist of social protection being provided in contexts of conflict and forced displacement, delivery by external agencies is almost always in parallel to rather than with government systems.
Maintaining funding for social assistance and wider forms of social protection during protracted crises is especially challenging. Countries experiencing conflict often face currency devaluations, inflation, and lower income from taxation that reduce fiscal space for social protection and undermine the real value of transfers.
Crisis-sensitive social assistance systems

In most countries, eligibility for social protection is based on citizenship and locality, undermining capacity to address or be sensitive to anthropocentric shocks and dynamic situations of displacement through social protection.
As a result of these factors, the dearth of evidence or analysis could suggest that decisions to work in parallel rather than with government are made because they align with received wisdoms about government capacities and ideologies, and their compatibility with the values, systems and procedures of international actors rather than because a robust examination of, for example, capacities has been carried out.
Inclusive SRSP is weak - even in stable settings - and rarely is sensitive to the differential impacts of crisis on specific vulnerable groups. There may be limited overlap between those targeted by social protection programmes (especially where categorical targeting is used) and those directly affected by shocks. Too often, receiving social protection leads to exclusion from other emergency assistance at the local level as local officials try to avoid any single household receiving more than one form of support.

Registries are deemed to be the magic bullet but, even in more stable situations, there are concerns about how frequently they are updated and recalibrated to reflect current situations.
Conflict sensitivity requires an understanding of when and how social protection operations especially targeting - can create or enflame local-level tensions and grievances. 


\section{Gaps in the evidence}

\section{- Crisis-resilient social assistance}

Evidence on sustaining social protection during protracted conflict is far more limited than that on climate shocks or even COVID-19. References offer patchy, rather than comprehensive or systematic, coverage of issues and places. Neither the wider governance of social protection systems, nor the political economy drivers that influence social protection programming, receive much attention.

Lessons about human resource capacities are the main focus of the literature but these draw on a conception of 'capacity' centred locally on individuals rather than organisations and systems. Studies discuss burn-out and turnover among aid workers exposed to trauma.

A major knowledge gap concerns how gender and other vulnerabilities influence the capacity, especially of staff, to sustain delivery, for example, whether there are differences in the capacities of men and women who administer social assistance when children are at home rather than in school during a crisis.

In many countries, the form of social protection being sustained is a subsidy system but we know little about the economic and political dynamics that affect specific instrument types. Not enough is known about the resilience of local and community actors and the mechanisms by which they connect with government systems.

\section{- Crisis-responsive social assistance}

Evidence is lacking to support concerns that the overall goals of international donors - notably for governments to take more responsibility for crisis response - do not align with governments' preoccupations about fiscal space, or the political ramifications of assisting displaced people before their own citizens. There are no identified empirical studies about how to realistically align expectations and objectives for SRSP; nor on how to increase alignment of policy and goals, and enhance interoperability. Very little empirical analysis exists of how impartiality / partiality or neutrality works in practice for SRSP; or of what could be done to integrate systems and overcome potential contradictory practices.

There is broad agreement that humanitarian cash and voucher assistance, social assistance, and programmes that build links between them (such as SRSP) need to pay greater attention to gender, age and disability (and other intersecting vulnerabilities) - but how to do this is unclear (Longhurst et al. 2020a).

\section{- Crisis-sensitive social assistance}

Getting delivery wrong produces community tensions or exacerbates conflict; this is known anecdotally, but is not robustly and comprehensively analysed. Targeting is a case in point, with concerns commonly raised about targeting refugees and the impacts on host communities.

While targeting effectiveness is fairly well-researched in stable development contexts, many gaps persist in FCAS: how to deal with a more complicated and dynamic underlying context; how to navigate gaps in understanding and identifying who is (most) 'in need'; how to overcome difficulties of understanding those needs; and how the assessment of needs changes as a result of acute shocks due to climate or conflict, or due to displacement. 


\section{Directions for BASIC Research}

Research on crisis-responsive social protection dominates the social assistance programming landscape. BASIC Research could, therefore, add greater value to knowledge and evidence generation by focusing on how social assistance can be crisis-resilient and crisis-sensitive.

\section{Research on crisis-resilience:}

- The resilience of social assistance systems in crisis situations. Which technical features of social protection systems and programmes enable (or disable) programme delivery to be sustained? Which delivery systems are the most commonly sustained? How can programmes and delivery systems be revised to sustain delivery during a crisis?

- The features of the wider enabling (or disabling) environment and how these affect the sustained delivery of existing programmes. How do the political dimensions of a particular crisis influence whether social protection is sustained? What are the political incentives to maintain delivery? What are the economic dimensions to sustaining social protection? What are the gender and inclusion dimensions that influence whether existing programmes can be sustained?

\section{Research on crisis-sensitivity:}

Making social assistance systems more crisis-sensitive requires serious treatment of targeting - both the decisions about who is deemed eligible to receive support, and the processes of identifying and enrolling recipients. Future research could address targeting along the design and delivery chain:

- How do crises affect poverty and how do those impacts influence who is targeted?

- How do targeting approaches used in humanitarian assistance and national social protection programmes perform?

- How is targeting perceived by recipients and communities (both humanitarian and national social protection programmes)?

- What are the Value for Money implications of targeting in practice?

For international agencies: What role do international agencies (humanitarian or development) play in enabling crisis-resilient and crisis-sensitive programme delivery by governments?

\section{Acknowledgements and Disclaimer}

This document was developed by the Better Assistance in Crises (BASIC) Research programme. BASIC is implemented by the Institute of Development Studies (IDS), the University of Sussex and the Centre for International Development and Training, funded by UKAid from the UK government. The views expressed in this document are entirely those of the authors and do not necessarily represent views or policies of the UK governments official policies.

(c) IDS copyright 2022. Copyright in the typographical arrangement and design rests with IDS.

This publication (excluding the logos) may be reproduced free of charge in any format or medium, provided that it is reproduced accurately and not used in a misleading context. The material must be acknowledged as IDS copyright with the title and source of the publication specified.

Published by IDS.

DOI: $\underline{10.19088 / B A S I C .2022 .019}$ 